\title{
Interactive comment on "Measurement Report: Size distributions of inorganic and organic components in particulate matter from a megacity in northern China: dependence upon seasons and pollution levels" by Yingze Tian et al.
}

\section{Yingze Tian et al.}

tianyingze@hotmail.com

Received and published: 27 October 2020

Thank you very much. The size distributions of organic components are not so much, especially for their variations dependence upon seasons and pollution levels, which is valuable for understanding their sources and fate. In the revision, we would conduct the size-resolved source apportionment of particulate matter (PM) based on analyses of both inorganic and organic markers. While there have been many studies of particle source apportionment in China, this study differs in analyzing a measurement dataset which is both size fractionated and chemically speciated. There are very few published 
studies of this type in the literature and our work shows major benefits of working with size-fractionated samples. The findings give valuable insights into both the sources of particles and the atmospheric processes affecting them.

Interactive comment on Atmos. Chem. Phys. Discuss., https://doi.org/10.5194/acp-2020-507, 2020.

Interactive

comment 